\title{
Mir1 is Highly Upregulated and Localized to Nuclei During Infectious Hyphal Growth in the Rice Blast Fungus
}

\author{
Lei Li, ${ }^{1}$ Sheng-Li Ding, ${ }^{1}$ Amir Sharon, ${ }^{2}$ Marc Orbach, ${ }^{3}$ and Jin-Rong $\mathrm{Xu}^{1}$ \\ ${ }^{1}$ Department of Botany and Plant Pathology, Purdue University, West Lafayette, IN 47907, U.S.A.; ${ }^{2}$ Department of Plant \\ Sciences, Tel Aviv University, Tel Aviv 69978, Israel; ${ }^{3}$ Department of Plant Sciences, University of Arizona, Tucson,
} AZ 85721, U.S.A.

Submitted 24 July 2006. Accepted 17 October 2006.

\begin{abstract}
Rice blast, caused by Magnaporthe grisea, is a devastating disease of rice throughout the world. Many recent molecular studies have focused on the early infection stages, but our knowledge about molecular events at the infectious hyphae stage is limited. In this study, 750 hygromycin-resistant transformants were isolated by transforming $M$. grisea Guy11 with a promoterless enhanced green fluorescent protein (EGFP) construct. In one of the transformants, L1320, EGFP signals were observed in the nuclei of infectious hyphae. The transforming vector was inserted in a predicted gene named $M I R 1$ and resulted in a Mir1 ${ }^{1-107}$. EGFP fusion. Mir1 is a low-complexity protein with no known protein domain and has no homolog in GenBank or other sequenced fungal genomes. Quantitative real-time reverse-transcriptase polymerase chain reaction analysis and expression assays of MIRI-EGFP fusion constructs indicated that the expression of $M I R 1$ was highly induced during plant infection. Deletion analyses identified a 458-bp region that was sufficient for the MIR1 promoter activity. Further characterization revealed that a 96-bp sequence was essential for the enhanced in planta expression. MIRI is an $M$. grisea-specific gene that is highly conserved among the field isolates belonging to the $M$. grisea species complex. The mirl mutants had no obvious defects in appressorial penetration and rice infection. When overexpressed with the RP27 promoter, nuclear localization of the Mir1EGFP fusion was observed in conidia and vegetative hyphae. These data suggest that the expression but not the nuclear localization of MIRI is specific to infectious hyphae and that reporter genes based on MIR1 may be suitable for monitoring infectious growth in $M$. grisea.
\end{abstract}

Additional keywords: appressorium, fungus-plant interaction, pathogenesis.

Rice blast, caused by Magnaporthe grisea, is one of the most severe fungal diseases of rice throughout the world (Talbot

Corresponding author: J.-R. Xu; Telephone: 765-496-6918; Fax: 765-4966918; E-mail: jinrong@ @urdue.edu

Current address of L. Li: Department of Plant Sciences, University of Arizona, Tucson, AZ 85721, U.S.A.

Nucleotide sequence data is available in the GenBank database under accession numbers XP_369115 for MIR1 (MG00129), XP_369114 for MG00130, XP_369113 for MG00131, and XP_369112 for MG00132.

* The $\boldsymbol{e}$-Xtra logo stands for "electronic extra" and indicates the HTML abstract available online contains supplemental material not included in the print edition. Two supplemental figures appear online.
2003; Valent and Chumley 1991). M. grisea has been developed as a model system to study fungus-plant interactions and is the first fungal plant pathogen to have its genome sequence published (Dean et al. 2005). The disease is initiated by the attachment and germination of conidia on rice leaves. The hardness and hydrophobicity of the rice leaf surface triggers the formation of a specialized infection structure called an appressorium. Enormous turgor pressure is generated inside appressoria as the physical force for plant penetration (de Jong et al. 1997). After penetration, the fungus forms bulbous, highly vacuolated infectious hyphae inside plant cells and further colonizes the rice tissues.

During the past decade, there have been extensive studies on molecular mechanisms involved in turgor generation and appressorium formation in $M$. grisea (Tucker and Talbot 2001). The cyclic AMP signaling and PMK1 mitogen-activated protein kinase pathways are critical for appressorium formation and plant penetration (Adachi and Hamer 1998; Talbot 2003). Over a dozen pathogenicity genes important for appressorial penetration have been functionally characterized, including PLS1, PDE1, MST12, GAS1, and GAS2 (Balhadere and Talbot 2001; Clergeot et al. 2001; Gilbert et al. 2006; Park et al. 2002; Xue et al. 2002). Apart from avirulence (AVR) genes (Bohnert et al. 2004; Farman and Leong 1998; Jia et al. 2000; Orbach et al. 2000), only a few genes, including $A B C 1$ and $H E X 1$, are known to be required for fungus-plant interactions after penetration (Soundararajan et al. 2004; Urban et al. 1999). Recently, a P-type ATPase gene (MgAPT2) involved in exocytosis and rapid induction of host defense responses has been identified (Gilbert et al. 2006). MgApt2-dependent exocytotic processes may play a role during plant infection. However, many of these genes are expressed and functional in vegetative hyphae. Except for the avr gene AVR-Pita (Jia et al. 2000), no other functionally characterized $M$. grisea genes are known to be specifically expressed in the infectious hyphae. Recently, serial analysis of gene expression (SAGE) and microarray analyses have been used to identify genes with altered expression levels in germinating conidia, appressoria, and mycelia under different growth conditions (Dean et al. 2005; Irie et al. 2003; Kamakura et al. 2002). However, there is no report on applying functional genomic approaches to identify $M$. grisea genes specifically expressed during plant infection. Reporter genes that are specific for infectious hyphae and suitable for monitoring infectious growth have not been identified in M. grisea.

In this study, an enhanced green fluorescent protein (EGFP)based promoter-trapping or gene-tagging approach was used to identify fungal genes that are expressed in different plant infection processes in M. grisea. In one transformant, L1320, 
EGFP signals were observed in the nuclei of infectious hyphae. Molecular characterization revealed that EGFP was fused inframe to the MIR1 gene in L1320. The expression of MIRI was significantly induced in infected plant tissues. Mutational analyses of the MIRI promoter revealed a 96-bp region that was essential for enhanced in planta expression of MIRI. MIRI is an M. grisea-specific nuclear protein that is well conserved in various rice blast isolates. When overexpressed with the RP27 promoter, nuclear localization of the Mir1-EGFP fusion was observed in conidia and vegetative hyphae of $M$. grisea, suggesting that the expression but not the nuclear localization of MIRl is specific to infectious hyphae. Therefore, the $M I R 1$ gene is suitable as a reporter gene for monitoring infectious growth and its promoter can be used to express genes in infectious hyphae.

\section{RESULTS}

\section{Identification of transformants expressing EGFP in infectious hyphae.}

Plasmid pCX12 carrying the promoter-less EGFP construct was linearized with HindIII and transformed into a wild-type strain Guy11. Among the 750 hygromycin-resistant transformants screened by onion epidermal penetration and rice seedling infection assays, 4 mutants were found to be defective in plant infection (Table 1). Six transformants had EGFP signals in appressoria or infectious hyphae (Table 1). In transformant L1306, EGFP signals were relatively strong in infectious hyphae but had no specific subcellular localization pattern (Fig. 1A). In contrast, nuclear localization of EGFP signals was observed in infectious hyphae of transformant L1320 (Fig. 1A), which had no detectable EGFP signals in conidia, germ tubes, appressoria, and vegetative hyphae (data not shown). Both L1306 and L1320 were normal in appressorium formation and still pathogenic on rice seedlings (Fig. 1B). To verify the nuclear localization in L1320, we transformed a histone H1EGFP fusion construct pMF280 (Freitag et al. 2004) into Guy11. In the resulting transformant mhg280 (Table 2), the same pattern of nuclear localization for EGFP signals was observed in infectious hyphae (data not shown). However, unlike L1320, vegetative hyphae and conidia of mhg280 also had strong fluorescence in nuclei.

Transformant L1320 has EGFP inserted in the MIRI gene.

To identify the $M$. grisea sequence conferring the EGFP expression and localization in L1320, plasmid rescue was used to recover the flanking sequences of the transforming vector pCX12. Plasmid pLL21 rescued from L1320 carried a 4-kb $M$. grisea genomic DNA fragment (Fig. 2A). Sequence analysis of pLL21 revealed that pCX12 was inserted in the open reading frame (ORF) of a predicted gene MG00129, which encodes a protein of 364 amino acids and was designated MIRl (for Magnaporthe infection-related gene 1). In transformant L1320, EGFP was fused in-frame with the first 107 amino acids of Mir1, and the expression of $M I R 1^{1-107}$-EGFP fusion likely was regulated by the $M I R l$ promoter (Fig. 2A). Southern hybridization with a MIRl fragment detected polymorphisms between Guy11 and transformant L1320 when digested with EcoRV and StuI but not with SalI (Fig. 2B). These data further confirmed that pCX12 was inserted at the N-terminal region of the MIRl gene in $\mathrm{L} 1320$.

To verify that the expression and nuclear localization of EGFP in transformant L1320 were conferred by its fusion with $M I R 1$, we generated a MIRl-EGFP fusion construct (pLL36) and a truncated $M I R 1^{1-122}-E G F P$ fusion construct (pLL37) that are both under the control of the MIRI promoter. After transforming pLL36 and pLL37 into Guy11, a total of 30 hygromycin-resistant transformants of each were isolated. Transformants

Table 1. Mutants of Magnaporthe grisea identified by penetration and infection assays

\begin{tabular}{lll}
\hline Transformant & \multicolumn{1}{c}{ Phenotype } & Green fluorescent protein expression \\
\hline L210 & No appressorium formation, nonpathogenic & In cytoplasm of infectious hyphae like structures \\
L279 & No defect in plant infection & Weakly in infectious hyphae \\
L324 & No defect in plant infection & In appressoria and infectious hyphae \\
L325 & No defect in plant infection & Weakly in infections hyphae \\
L370 & Nonpathogenic, form appressoria & No enhanced green fluorescent protein (EGFP) signal \\
L398 & No appressorium formation, nonpathogenic & No EGFP signal \\
L1287 & Reduced in virulence, rare lesions & No EGFP signal \\
L1306 & No defect in plant infection & Only in infectious hyphae \\
L1320 & No defect in plant infection & In the nuclei of infectious hyphae \\
\hline
\end{tabular}

Table 2. Wild-type strains and transformants of Magnaporthe grisea used in this study

\begin{tabular}{lll}
\hline Strains & \multicolumn{1}{c}{ Description } & Reference \\
\hline Guy11 & Wild type, MAT1-2 & Valent and Chumley 1991 \\
mhg280 & Guy11 transformed with pMF280 (histone H1-EGFP) & This study \\
mir16 & mirl gene replacement mutant of Guy11 & This study \\
mir22 & mirl gene replacement mutant of Guy11 & This study \\
mir30 & mirl gene replacement mutant of Guy11 & This study \\
mir41 & mirl gene replacement mutant of Guy11 & This study \\
mir3 & Ectopic transformant of pLL44 of Guy11 & This study \\
M36-6 & Complemented transformant of mir16 & This study \\
ML36-1 & Full-length Mir1-EGFP fusion (pLL36) in Guy11 & This study \\
M37-30 & 1.5-kb MIR1 promoter-MIR1 1 -122-EGFP (pLL37) in mir16 & This study \\
ML46-11 & RP27-Mir1-EGFP (pLL46) in Guy11 & This study \\
ML47-1 & 1.5-kb MIR1 promoter -EGFP (pLL47) in Guy11 & This study \\
ML48 & 1.1-kb MIR1 promoter -EGFP (pLL48) in Guy11 & This study \\
ML49 & 756-bp MIR1 promoter -EGFP (pLL49) in Guy11 & This study \\
ML50 & 458-bp MIR1 promoter -EGFP (pLL50) in Guy11 & This study \\
ML51 & 209-bp MIR1 promoter -EGFP (pLL51) in Guy11 & This study \\
ML60 & Region A deletion in the 458-bp MIR1 promoter (pLL60) & This study \\
ML61 & Region B deletion in the 458-bp MIR1 promoter (pLL61) & This study \\
\hline
\end{tabular}

${ }^{\mathrm{a}} \mathrm{EGFP}=$ enhanced green fluorescent protein. 
ML36-1, ML36-10, and ML37-30 (Table 2) contained a single copy of pLL36 or pLL37 according to Southern blot analyses (data not shown). In onion epidermal penetration assays, all these transformants had strong fluorescence signals in the nuclei of infectious hyphae (Fig. 2C). Similar to transformant L1320, EGFP signals were either not detectable or very weak in conidia (Fig. 2C), appressoria, and vegetative hyphae of ML36-1, ML36-10, and ML37-30 (data not shown). Enhanced EGFP signals in nuclei were observed only in infectious hyphae formed inside plant cells. Thus, MIRl encodes a nuclear protein that is highly expressed in infectious hyphae. The $\mathrm{N}$ terminal portion of Mir1 protein must be sufficient for

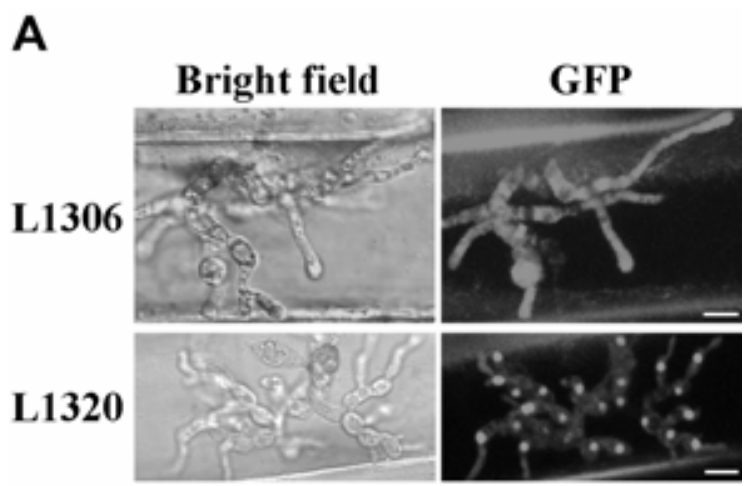

B
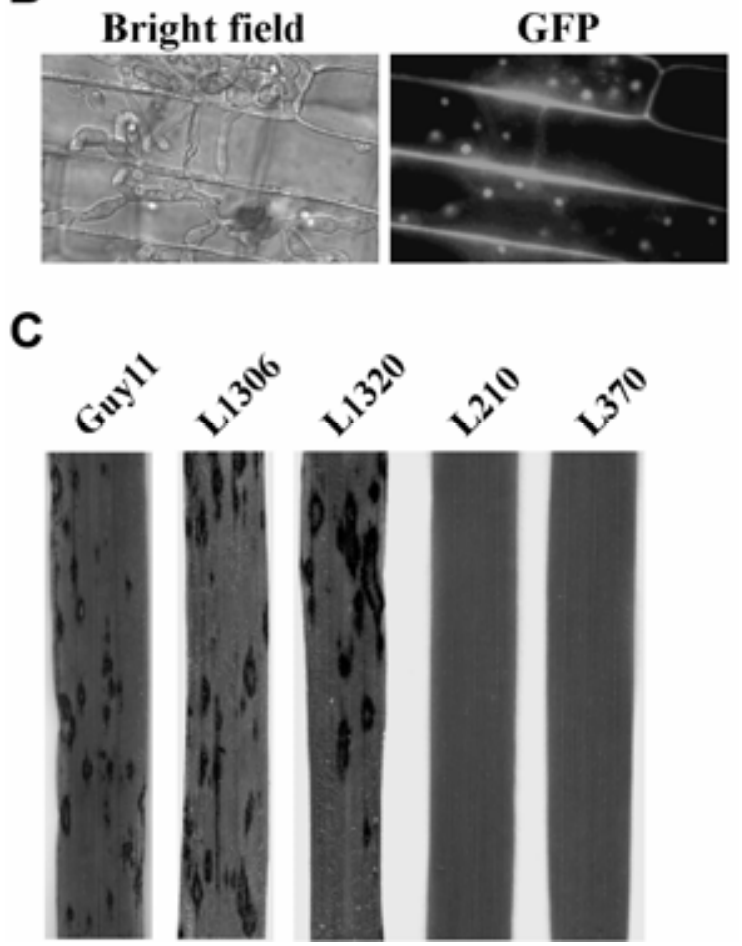

Fig. 1. Onion epidermis penetration and rice infection assays. A, Onion epidermis were inoculated with conidia of the transformants L1306 and L1320. Both mutants L1306 and L1320 penetrated onion epidermal cells and expressed enhanced green fluorescent protein (EGFP) in infectious hyphae. EGFP signals were detected in the cytoplasm in L1306 but localized to the nuclei in L1320. Bar $=10 \mu \mathrm{m}$. B, Infectious hyphae formed by L1320 inside rice leaf sheath epidermal cells. EGFP signals were observed in nuclei. C, Rice infection assays. Seedlings of rice cv. CO39 were sprayed with conidia of the wild-type strain Guy11 and mutants L210, L1306, L1320, and L398. Similar to Guy11, mutants L1306 and L1320 caused numerous blast lesions on rice leaves. Lesions were not observed on leaves inoculated with mutants L210 and L398. directing its nuclear localization in infectious hyphae because the Mir1-EGFP fusion in L1320 or pLL37 was truncated and lacked the downstream predicted bipartite nuclear localization signal (NLS) (Fig. 2A).

The expression of MIRI is enhanced during plant infection.

To further confirm the upregulation of MIRl expression during rice infection, quantitative real-time reverse-transcriptase polymerase chain reaction (RT-PCR) was performed to determine relative transcriptional levels of MIRI in infected rice leaves and vegetative hyphae grown in complete medium (CM). The amplification of the $M$. grisea actin gene $M g A C T 1$

A

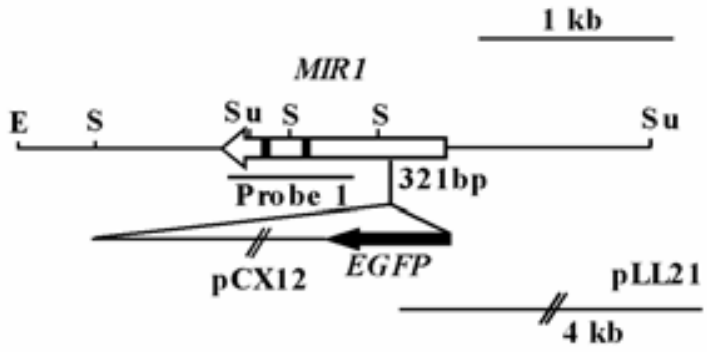

B

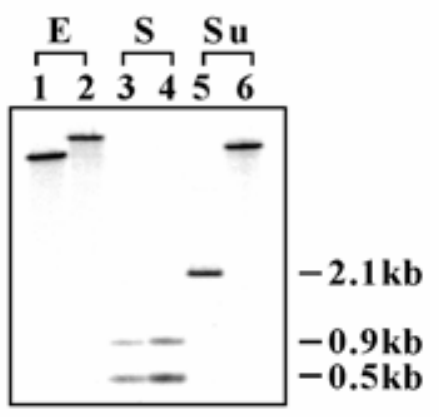

C

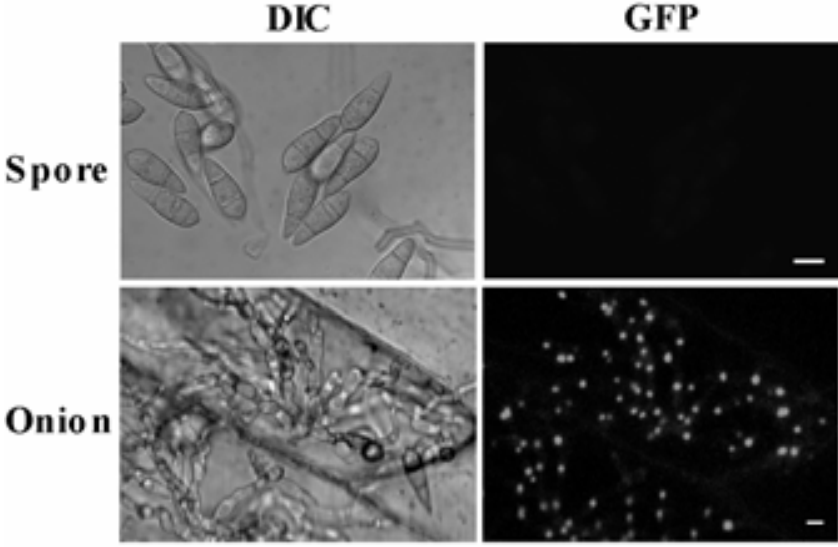

Fig. 2. Disruption of the MIR1 gene in mutant L1320. A, Schematic diagram of the genomic sequence of the MIR1 gene (empty arrow). The filled arrow bars marked the enhanced green fluorescent protein (EGFP). Two shaded boxes were putative bipartite nuclear localization signal sequences (residues 230 to 247 and 289 to 306). The insertion site of the transforming vector pCX12 is 321 bp downstream from the start codon of MIRl. E, EcoRV; S, SalI; Su, StuI. Plasmid pLL21 is the plasmid rescued from L1320. B, Southern blot of genomic DNA of Guy11 (lanes 1, 3, and 5) and L1320 (lane 2, 4, and 6) was hybridized with probe 1 amplified with primers MG129F1 and MG129R2. C, Transformant ML36 was observed by DIC and epifluorescent microscopy. Strong EGFP signals were observed in the nuclei of infectious hyphae that developed inside onion epidermal cells but no or only weak EGFP signals were detectable in asexual spores. $\mathrm{Bar}=10 \mu \mathrm{m}$. 
was used as the endogenous reference for normalization. In comparison with the expression level of MIRI in the CM cultures, a 165-fold increase of MIR1 expression, on average, was detected in the infected rice tissues at 5 days postinoculation (dpi) in three replicates (Fig. 3A).

To experimentally examine the $M I R I$ promoter activity, a 1.5 -kb fragment upstream of the MIRl gene was cloned in front of the EGFP reporter as pLL47 and transformed into Guy11. In transformants carrying a single copy of pLL47 (ML47-1) (Table 2), EGFP signals were very weak or not visible in the conidia and germ tubes (Fig. 3B) when germinated on artificial surfaces. However, strong EGFP signals were observed in the infectious hyphae formed by ML47-1 in the onion epidermal cells (Fig. 3B), indicating that this $1.5-\mathrm{kb}$ fragment contained the promoter elements required for the upregulation of MIR1 in infectious hyphae. Because the MIRl ORF sequence was absent in pLL47, nuclear localization was not observed in ML47 (Fig. 3B).

\section{The 458-bp upstream sequence is sufficient} for enhanced in planta expression of MIR1.

Plasmids pLL48, pLL49, pLL50, and pLL51 were constructed by fusing the EGFP reporter gene with a $1.1-\mathrm{kb}, 756-$ bp, 458-bp, or 209-bp fragment upstream of the MIR1 ORF, respectively (Fig. 4A). All these plasmids were constructed by yeast gap repair (Bourett et al. 2002; Raymond et al. 2002) and

A

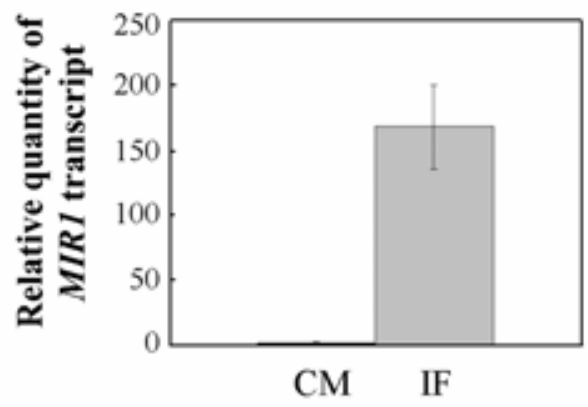

B

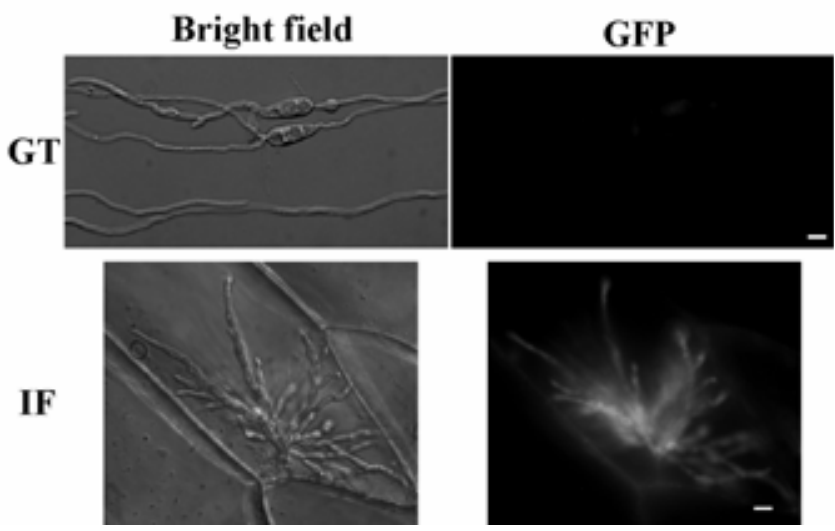

Fig. 3. Induced expression of $M I R 1$ during plant infection. A, Relative quantity of MIRI transcripts in vegetative hyphae grown on complete medium (CM) and in infected rice leaves (IF) were quantified by real-time reverse-transcriptase polymerase chain reaction. B, Conidia of ML47 were germinated on a slide glass (upper panel) or on onion epidermis (lower panel) and observed under bright-field or UV light of an epifluorescence microscope. Strong enhanced green fluorescent protein (EGFP) signals were observed in infectious hyphae inside onion epidermal cells but no or only weak EGFP signals were detectable in conidia and germ tubes. transformed into Guy11. Over 10 transformants from each construct were analyzed by Southern blot hybridization (data not shown). At least one transformant with a single copy of the corresponding transforming vector (Table 2) was selected and assayed for promoter activities. Transformants ML48, ML49, and ML50 had EGFP expression levels similar to ML47 in infectious hyphae that developed inside onion epidermal cells (Fig. 4B). In transformant ML51, however, no or only very weak EGFP signals were detected in infectious hyphae (Fig. 4B). In all these experiments, autofluorescence related to plant defense responses was observed in plant cell walls and at the penetration point where papilla was developed (Fig. 4B). In all these transformants, vegetative hyphae and conidia had no or

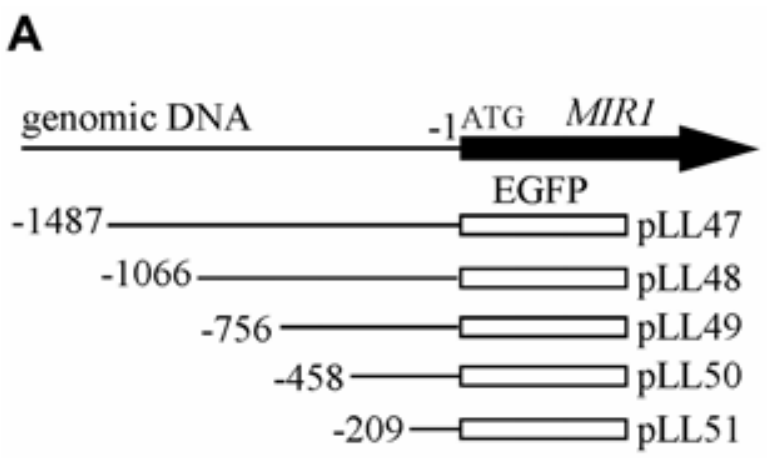

B

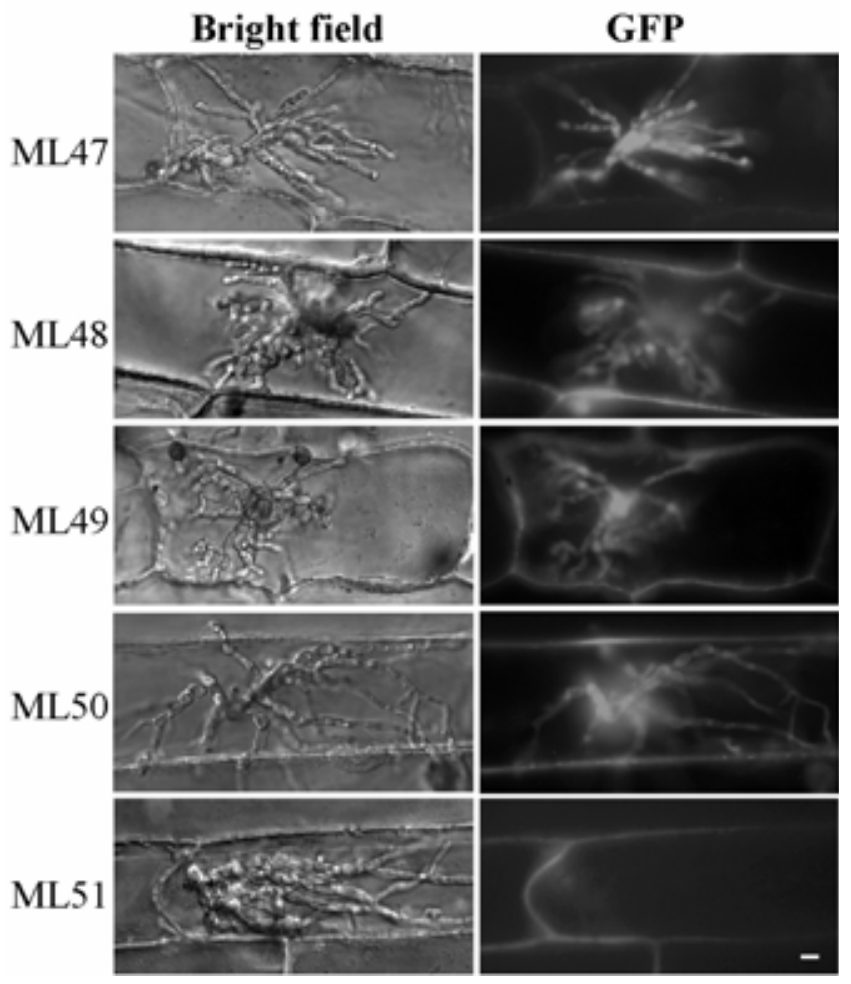

Fig. 4. Functional characterization of the MIRl promoter. A, Schematic diagrams of constructs containing different upstream sequences of MIRI fused with enhanced green fluorescent protein (EGFP). Black arrow indicates the MIR1 gene. Open boxes mark the EGFP open reading frame. The length of each promoter region was labeled on the left in reference to the start codon of MIR1. B, Infectious hyphae developed by the wild-type strain Guy11 and transformants containing a single copy of pLL47 (ML47), pLL48 (ML48), pLL49 (ML49), pLL50 (ML50), and pLL51 (ML51) inside onion epidermal cells were examined by epifluorescent microscopy. The strength of EGFP signals in transformants ML48, ML49, and ML50 was similar to that of ML47. In ML51, only very weak or no EGFP signals were observed. Bar $=10 \mu \mathrm{m}$. 
only very weak EGFP signals (data not shown). These results suggest that the upstream sequence of MIRI ( -1 to -458$)$ carried by pLL50 contains essential regulatory elements of the MIRl promoter.

\section{A}

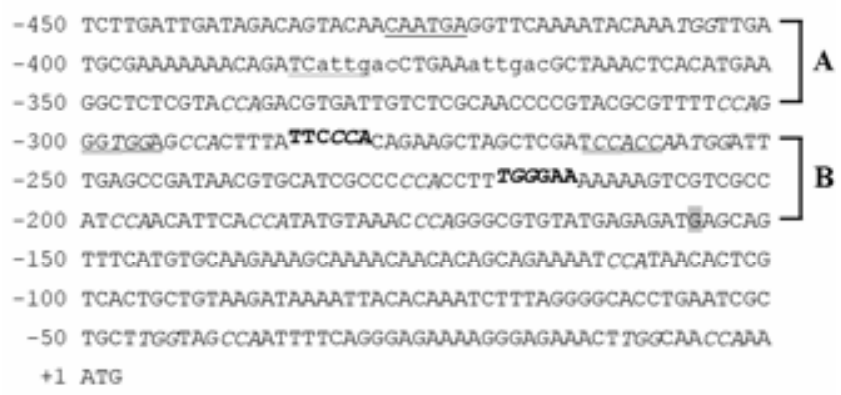

B

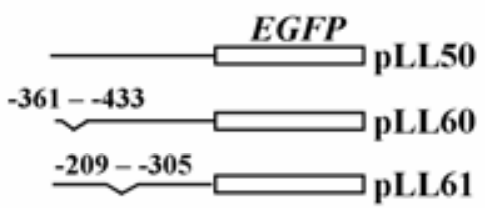

C

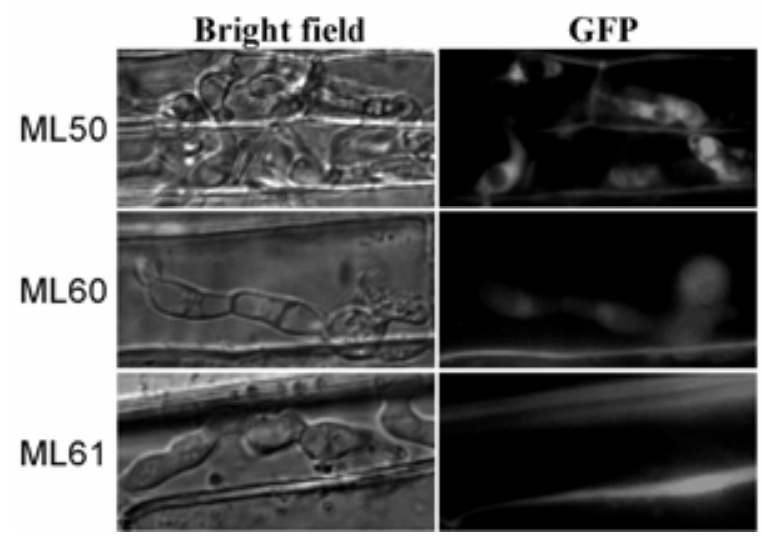

Fig. 5. Mutational analysis of the $M I R l$ promoter. A, Direct repeats of attgac (in lower case) and inverted repeats of CAATGA (underlined), GGTGGA (double lined), and TTCCCA (in bold) were identified in the MIR1 promoter sequence. The start codon of $M I R 1$ is designated ' +1 '. The transcription initiation site is shaded in gray and the CCA triplets are in italics. B, Plasmids pLL60 and pLL61 were constructs generated by deleting region A ( -361 to $433)$ and region B (-209 to -305), respectively, in the 458-bp MIR1 promoter sequence. Open boxes indicate enhanced green fluorescent protein (EGFP) open reading frame. $\mathbf{C}$, In infectious hyphae that formed inside rice sheath epidermal cells, EGFP signals were not detectable in ML61. In ML60, EGFP signals were observed but at a reduced level in comparison to that of ML50.

\section{A 96-bp promoter region is critical for the MIR1 promoter activity.}

To identify the transcription initiation site of $M I R 1$, we conducted 5'-RACE (rapid amplification of cDNA ends) with RNA isolated from infected rice leaves harvested at 5 dpi. Sequence analysis of the resulting 5'-RACE PCR products revealed that the transcription initiation site is 156 bp upstream from the start codon of MIRl (Fig. 5A). Thus, the critical elements of the MIRl promoter must be between -157 and -458 . Based on the nucleotide sequence, we then generated EGFP reporter constructs pLL60 and pLL61 (Fig. 5B) in which region $\mathrm{A}(-361$ to -433$)$ and region $\mathrm{B}(-209$ to -305$)$, respectively, were deleted from the 458-bp minimal MIRl promoter carried by pLL50. Region A contained two inverted repeats of CAATGA and two direct repeats of ATTGAC. Region B had inverted repeats of TTCCCA and TCCACC (Fig. 5A). In penetration assays with rice leaf sheath epidermal cells, EGFP signals were still detectable but markedly reduced in infectious hyphae formed by transformant ML60 expressing pLL60 (Fig. 5C). However, in transformant ML61 expressing pLL61, only very weak or no EGFP signals were observed in infectious hyphae that developed inside rice leaf sheath epidermal cells (Fig. 5C). These data indicate that region $\mathrm{B}$ but not region $\mathrm{A}$ contains critical regulatory elements of the $M I R 1$ promoter.

MIRI is a novel gene unique to $M$. grisea.

MIRl had no significant homolog $(e$ value $<1 \mathrm{e}-5)$ in the GenBank or other fungal genomes that have been sequenced, including Fusarium graminearum, Sclerotinia sclerotiorum, Botrytis cinerea, and Neurospora crassa. A Southern blot containing DNA samples from $28 \mathrm{M}$. grisea strains isolated from different hosts (Kang et al. 1995; Sweigard et al. 1995) was probed with the MIRI gene. In all the isolates except G-231 (a Cyperus rotundus isolate), at least one hybridizing band was detected in the EcoRI digests (Fig. 6). All the rice isolates and strains isolated from Eleusine and Panicum spp. had the same 6-kb band (Fig. 6). When the same blot was stripped and reprobed with the $M g A C T 1$ actin gene amplified with primer Act5F and Act6R, G-231 had a much weaker hybridization band than the other strains (Fig. 6). All but one rice isolate (A598, lane 27) had a band larger than $12 \mathrm{~kb}$. The fragment of the MIRI ORF and its 1.5 upstream region was sequenced from P-131 (Peng et al. 1994), a rice blast field isolate from Japan. Only two nucleotide differences between Guy11 and P131 were identified. The single base pair difference located in the MIRl ORF, however, does not affect the amino acid sequence. These data indicate that $M I R l$ is highly conserved among the rice blast isolates and widely distributed in $M$. grisea strains isolated from different hosts or regions.

The Mir1 protein sequence was analyzed with various programs, including PSORT and PFSCAN (Nakai and Horton

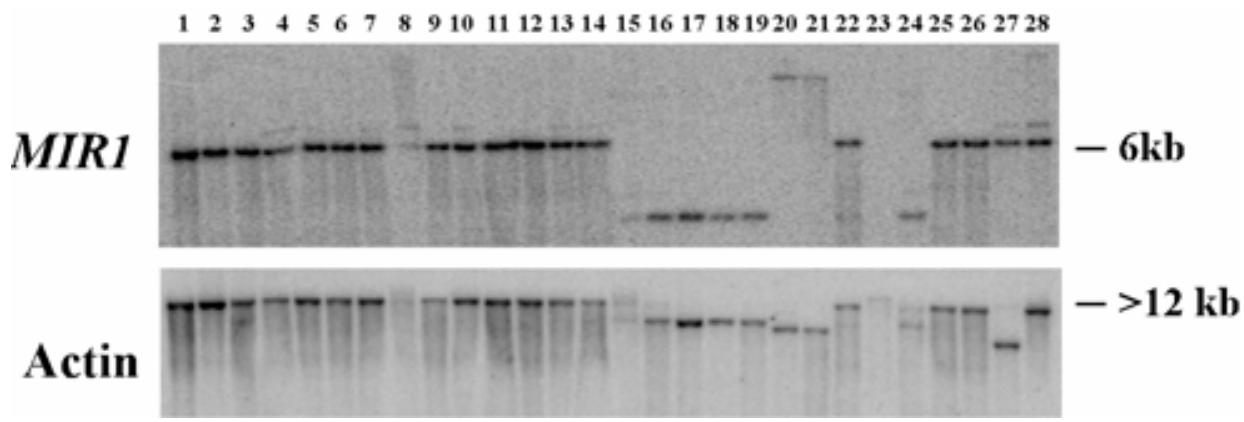

Fig. 6. Southern blot of genomic DNA from different Magnaporthe grisea field isolates hybridized with the $M I R 1$ gene (upper panel) and the $M g A C T 1$ actin gene (lower panel). Lanes 1-28 were loaded with EcoRI-digested DNA from isolates O-137, KJ201, Guy11, O-42, O-17, O-190, O-224, O-315, G-158, G201, G-176, G-219, G-220, G-221, G-156, G-11, G-163, G-223, G-189, G-81, G-222, G-224, G-231, G-1, G-17, T-47, A598, and LO3-8, respectively. 
1999; Pagni et al. 2004). No known domain or motif was identified except the putative NLS sequences (Fig. 2A). Mir1 is a protein of low sequence complexity. It has a low content of hydrophobic amino acids (15\%) and a high proportion of polar and charged amino acids $(64 \%)$. These features resemble the characteristics of "intrinsic disordered" or "nonstructured" proteins (Dyson and Wright 2005) that lack properly folded and organized three-dimensional structures. Several programs, including FoldIndex, DisEMBL, GLOBPROT 2, and

A

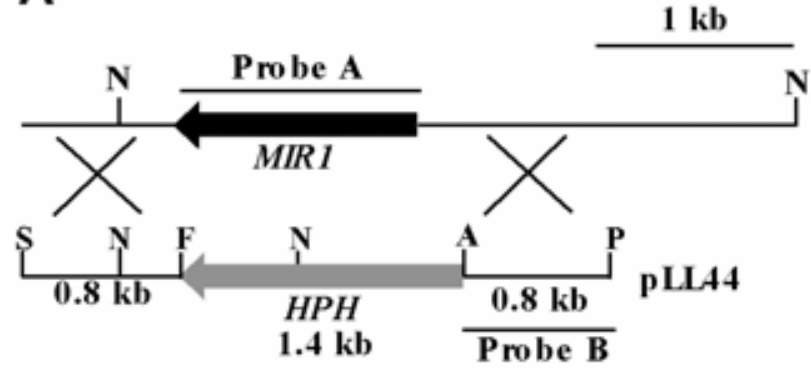

B

Probe A

12334567

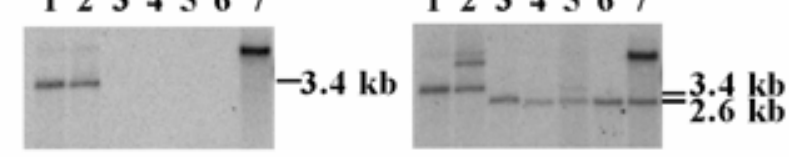

C

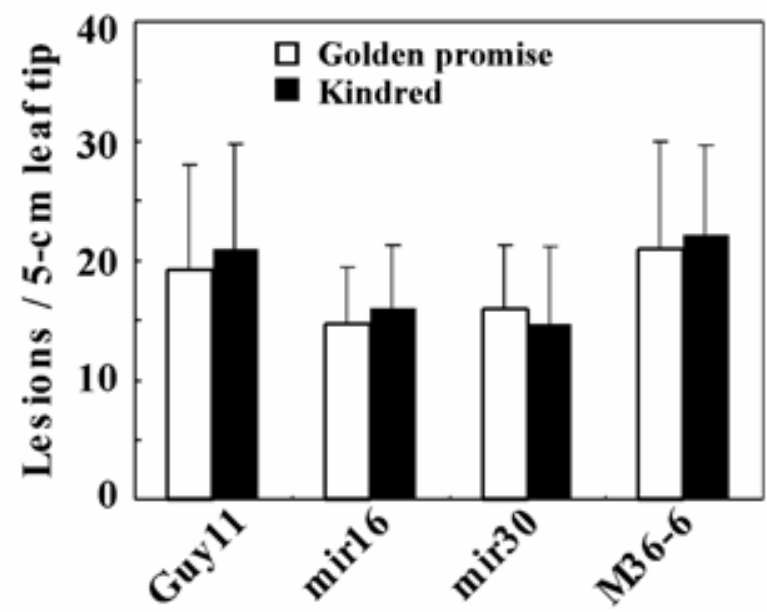

Fig. 7. MIRl gene replacement construct and mutants. A, Schematic diagram of the genomic region of MIRI and the gene replacement construct pLL44. The black arrow indicated the open reading frame of $M I R$. B, Southern blot analysis of the mirl knockout mutants. Lanes 1 through 7 were NcoIdigested genomic DNA of the wild-type Guy11, ectopic transformant mir3, four mirl knockout mutants (mir16, mir30, mir22, and mir41), and a complementation strain (M36-6). A 3.4-kb band was detected in Guy11 and mir3 but not in mir16, mir30, mir22, or mir41 when hybridized with probe A. When hybridized with probe B (right), a 2.6-kb but not the wild-type 3.4-kb band was detected in the mirl mutants. C, Barley seedlings of cvs. Golden Promise and Kindred Lesion were inoculated with conidia of Guy11, mir16, mir30, and M36-6. Lesion formation was examined on infected rice leaves 7 days postinoculation. Means and standard errors were calculated from at least three independent experiments.
DISOPRED2, all predicted that Mir1 contained large segments of disordered regions.

MIR1 is not essential for pathogenesis in M. grisea.

To determine the function of MIRl in $M$. grisea, the MIRI gene replacement construct pLL44 (7A) was transformed into Guy11. Among 60 hygromycin-resistant transformants screened, 4 mirl gene-replacement mutants (mir16, mir22, mir30, and mir41) (Table 2) were identified and confirmed by Southern blot analysis (Fig. 7B). The mirl mutants were normal in vegetative growth and conidiation. In penetration assays with onion and rice leaf sheath epidermal cells, the mirl mutants were able to form melanized appressoria, penetrate plant cells, and develop infectious hyphae as efficiently as the wildtype strain Guy11 (data not shown). The mirl mutants caused typical blast lesions on seedlings of rice cv. CO-39. No statistically significant changes in virulence were observed in the mirl mutants (data not shown). The mirl mutants also were able to infect barley cvs. Golden Promise and Kindred (Fig. 7C). Therefore, MIRl is dispensable for pathogenesis in $M$. grisea.

\section{Nuclear localization of the Mir1-EGFP fusion in overexpression transformants.}

We also generated an overexpression vector pLL46, in which the MIRl-EGFP fusion was controlled by the strong constitutive RP27 promoter (Bourett et al. 2002). In Guy11 transformants expressing pLL46, EGFP signals were observed in the nuclei of conidia (Fig. 8) and vegetative hyphae (data not shown), indicating that the expression of MIRl but not its nuclear localization is specific to infectious hyphae. To determine whether MIRl localizes to nuclei when expressed in other plant-pathogenic fungi, the MIRl-EGFP fusion construct pLL46 was transformed into the F. graminearum $\mathrm{PH}-1$ and Colletotrichum gloeosporioides Cga3.1.3. In the resulting transformants of PH-1 and Cga3.1.3 expressing pLL46, EGFP signals were observed in the nuclei of conidia (Fig. 8) and vegetative hyphae (data not shown). These data further indicate that the localization of Mir1 to nuclei, when expressed by the RP27 promoter, is not specific to infectious hyphae of $M$. grisea. Therefore, the function of Mir1 must be

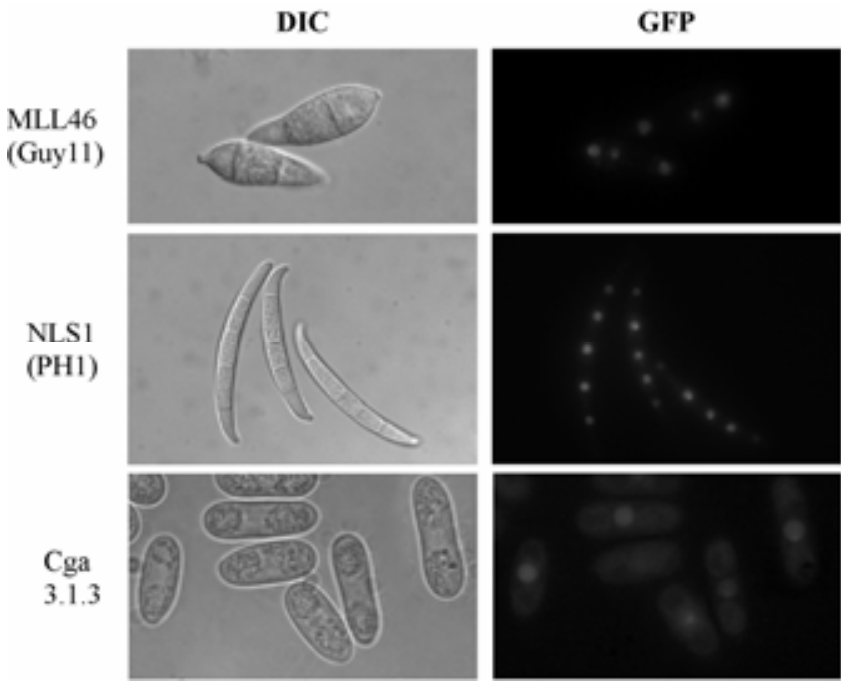

Fig. 8. Overexpression of the Mir1-enhanced green fluorescent protein (EGFP) fusion with the strong constitutive RP27 promoter. ML46, NLS1, and Cga313 were transformants of Magnaporthe grisea, Fusarium graminearum, and Colletotrichum gloeosporioides, respectively, expressing pLL46 (RP27-MIR1-EGFP). Nuclear localization of EGFP signals was observed in the conidia and vegetative hyphae of ML46, NLS1, and Cga3.1.3 when examined under epifluorescence microscopy. Scale bar $=10 \mu \mathrm{m}$. 
regulated at the transcriptional level. The Mir1 promoter is not active during vegetative growth and could be used as a reporter for infectious hyphae.

\section{DISCUSSION}

Several transformants with defects in plant infection or expression of EGFP during plant infection were identified in this study. In transformant L1320 that was characterized in detail, EGFP signals were observed in infectious hyphae and localized to nuclei. The MIR1 gene disrupted in L1320 is unique to $M$. grisea. The expression level of MIRl was increased significantly during plant infection. Although it is dispensable for plant infection under laboratory conditions, MIRl may be important for the fitness and virulence of $M$. grisea in field conditions because of its upregulation during plant infection and well-conserved homologs in $M$. grisea isolates. Among the field isolates examined, only G-231 had no hybridization band when probed with the MIRl gene (Fig. 6). However, recent studies have indicated that G-231 may not be a member of the M. grisea species complex (S. Kang, personal communication).

MIRI has no homologous sequences in GenBank and it contains no known protein domain or motif other than the NLSs. Therefore, it is impossible to predict the exact biological function of Mir1. However, several short peptide repeats such as direct repeats of ASKR, KROR, and SDDESxxDDD (Supplemental Fig. 1) were identified in the Mir1 sequence by the SAPS program (Brendel et al. 1992). The predicted NCU07751 protein of $N$. crassa has a low homology $(e$ value $=$ 1e-5) with MIR1 but it lacks these repeats. We also found that Mir1 meets the criteria of a group of intrinsically unstructured proteins (Dyson and Wright 2005). These intrinsically unstructured proteins appear as long stretches of amino acids that likely are unfolded in solution or adopt nonglobular structures (Dyson and Wright 2005). Other unstructured proteins have been implicated in different biological functions in various organisms, such as regulation of transcription and translation, cellular signaling, protein phosphorylation, the regulation of the self-assembly of large multiprotein complexes, and chaperones for other proteins or RNA molecules (Wright and Dyson 1999). Some of these unstructured proteins can undergo coupled folding with interacting proteins and transform themselves into more ordered states (Dyson and Wright 2005). In $M$. grisea, Mir1 may undergo similar conformation changes by interacting with proteins that facilitate its nuclear localization or co-localize to nuclei in infectious hyphae. Unfortunately, we failed to identify any $M I R l$-interacting clones by screening yeast two-hybrid libraries constructed with RNA isolated from appressoria and vegetative hyphae (data not shown).

To date, there are no reporter constructs in $M$. grisea that are specific for infectious hyphae. Because the expression of MIRI is not detectable in vegetative hyphae and increased over 150fold during plant infection (Fig. 3), the MIRl-EGFP fusion is well suitable as a reporter to monitor infectious hyphal growth. In other pathogenic fungi, dozens of genes that are upregulated during infection have been isolated by subtractive hybridization, differential display, and promoter trapping (Aichinger et al. 2003; Basse et al. 2000; Cramer and Lawrence 2004; Thara et al. 2003). In the maize pathogen Ustilago maydis, a group of genes encoding secreted proteins, including migl and the mig2 cluster, are highly induced in leaf tumors (Basse et al. 2000). The mig2 cluster contains five similar genes known as mig2-1 to mig2-5 (Basse et al. 2002). The mig2-6 gene is unlinked to the mig2 cluster but shares the homology and expression pattern with the mig2 genes (Farfsing et al. 2005). However, deletions of these mig genes individually or in com- bination have no effect on pathogenicity in $U$. maydis (Basse et al. 2000, 2002; Farfsing et al. 2005). In addition to the mig2 gene cluster, other plant-regulated genes were identified by promoter trapping in U. maydis (Aichinger et al. 2003). The pig2 gene, encoding a putative protein disulfide isomerase, and several other pig genes (pig3, pig4, pig5, and pig7) located in the $p$ locus also are upregulated during plant infection (Aichinger et al. 2003). Similar to the mig genes, deletion of pig 2 or other individual pig genes or the entire $p$ locus (with ectopic introduction of an essential gene in the locus) had no effect on the virulence of the fungus (Aichinger et al. 2003). In the $M$. grisea genome, three predicted genes adjacent to MIRI, MG00130, MG00131, and MG00132, have no homolog in GenBank or other sequenced fungal genomes. This cluster of $M$. grisea-specific genes is flanked by MG000128 and MG00133 that encode conserved hypothetical proteins.

In $M$. grisea, promoter elements responsible for in plantaspecific or induced expression have not been characterized previously. In this study, we identified a 458-bp fragment that is sufficient to control the MIRl expression in infectious hyphae. Unlike region A (Fig. 5, $72 \mathrm{bp}$ ) that played a minor role in regulating MIRl expression, the 97-bp region B is critical for its induced expression during plant infection. When the region B sequence (-305 to -209) was analyzed with the Tfsearch program, several putative TF binding sites were identified (Supplemental Fig. 2). These and additional putative transcription factor binding sites also were identified by the TESS program. Interestingly, the predicted gene MG00130 and MIRl are opposite to each other (head to head) and only $900 \mathrm{bp}$ apart. The sequence located between MIRl and MG000130 may contain promoter elements, such as the inverted repeats (Fig. 5) identified in region B, that are common for regulating the expression of these two genes. Similar to MIR1, MG00130 has no matching expressed sequence tag sequences, suggesting that they are not expressed in conidia and vegetative hyphae grown under various conditions (Ebbole et al. 2004). Our preliminary data indicated that the expression level of MG000130, similar to that of MIR1, increased over 100-fold in infectious hyphae (S.-L. Ding and J.-R. Xu, unpublished data).

We also identified seven repeats of 5'-CCA-3' in region B of the MIRl promoter. Two of them are tandem repeats and the others were evenly distributed (Fig. 5). Many CCA repeats also were found in the promoter regions of the $A B C 1, A V R$ Pita, and MHPl genes that have induced or enhanced expression levels during plant infection (Kim et al. 2005; Orbach et al. 2000; Urban et al. 1999). In U. maydis, promoters of the mig1, mig2-1, and mig2-5 genes are subject to both positive and negative regulation during in planta growth (Basse et al. 2002). The mig2-5 promoter has several repeats of $5^{\prime}-\mathrm{CCA}-3^{\prime}$ motifs that are critical for the induced expression of mig2-5 during infection of maize plants (Farfsing et al. 2005). However, the transcription factor binding to 5'-CCA-3' has not been identified (Farfsing et al. 2005). In M. grisea, the 5'CCA-3' repeats in the 96-bp region upstream of MIRl also probably play important roles in the induced expression of MIRl in planta. Both inverted repeats found in region B contain $5^{\prime}-\mathrm{CCA}-3^{\prime}$. To date, the only transcription factor known to be involved in infectious hyphal growth in $M$. grisea is Mst12 (Park et al. 2002). Unfortunately, no genes regulated by Mst12 have been identified and its binding site is not clear. Our data indicate that the expression of MIRl is highly induced during plant infection. Further characterization of the $M I R l$ promoter may lead to the identification of the transcription factor binding site and corresponding transformation factor that is responsible for the enhanced expression of $M I R 1$ in infectious hyphae. 


\section{MATERIALS AND METHODS}

Fungal strains, transformation, and growth conditions.

The wild-type strain Guy11 and transformants used in this study (Table 2) were cultured on oatmeal agar plates at $25^{\circ} \mathrm{C}$ under fluorescent light (Xue et al. 2002). Mycelium was collected by filtration through Miracloth (Calbiochem, La Jolla, CA, U.S.A.) from 2-day-old $5 \times$ YEG $(0.5 \%$ yeast extract, $1 \%$ glucose) or complete medium cultures (Zhao et al. 2005) and used for isolation of fungal DNA and protoplasts. Media were supplemented with hygromycin B at $250 \mu \mathrm{g} / \mathrm{ml}$ or zeocin at $100 \mu \mathrm{g} / \mathrm{ml}$ (Invitrogen, Carlsbad, CA, U.S.A.) for selecting hygromycin-resistant and zeocin-resistant transformants, respectively. Transformation, monoconidial culture isolation, and genetic crosses of $M$. grisea were performed as described previously (Talbot et al. 1993). Cultivation and transformation of the F. graminearum wild-type strain PH-1 (Trail and Common 2000) and related transformants were performed as described previously (Hou et al. 2002). The C. gloeosporioides f. sp. aeschynomene wild-type strain Cga3.1.3 and the transformants generated in this study were cultured at $28^{\circ} \mathrm{C}$ on EMS agar (Barhoom and Sharon 2004).

A Southern blot containing EcoRI-digested genomic DNA samples from 28 Magnaporthe isolates (Kang et al. 1995; Sweigard et al. 1995) was provided by S. Kang at Pennsylvania State University. These representative Magnaporthe strains included 10 rice isolates: O-137 (China), KJ201 (South Korea), Guy11 (French Guyana), O-42 (Japan), O-17 (Japan), O-190 (South Korea), O-224 (Nigeria), O-315 (Cameroon), A598 (U.S.A.), and LO3-8 (U.S.A.); 5 Digitaria isolates: G-156 (Brazil), G-11 (Japan), G-163 (Philippines), G-189 (U.S.A.), and G-1 (U.S.A.); 5 Pennisetum isolates: G221 (Japan), G-223 (Brukina Faso), G-81 (U.S.A.), G-222
(Mali), and G-224 (Ivory Coast); 2 Panicum isolates: G-219 (India) and G-220 (India); 2 Eleusine isolates: G-201 (Brazil) and G-176 (Nepal); 1 wheat isolate: T-47 (Brazil); 1 Feral Triticale isolate: G-158 (Brazil); 1 Eragrostis curvula isolate: G-17 (Japan); and 1 Cyperus rotundus isolate: G-231 (Philippines).

\section{Construction of the promoter-trapping vector.}

To construct the promoter-trapping vector $\mathrm{pCX} 12$, a $0.9-\mathrm{kb}$ trpC terminator from Aspergillus nidulans was released from pAC905 (Zheng et al. 2000) and cloned between the BamHI and $\mathrm{Xba \textrm {I }}$ sites of pCB1004 (Carroll et al. 1994) as pCB1004T. The 0.7-kb EGFP ORF from pEGFP (BD Bioscience Clontech, San Jose, CA, U.S.A.) then was cloned upstream from the trpC terminator on $\mathrm{pCB} 1004 \mathrm{~T}$ to generate $\mathrm{pCX} 12$. Plasmid pCX12 was linearized with HindIII and transformed into protoplasts of Guy11.

\section{Molecular manipulations and sequence analyses.}

Standard molecular biology procedures were followed for DNA gel blot analyses and enzymatic manipulations with DNAs (Sambrook and Russell 2001). For plasmid rescue, the self-ligation mixture of PstI-digested L1320 genomic DNA was transformed into the XL1-Blue cells. For determining the copy number of transforming vector in the genome, genomic DNA samples were digested with $S a c$ I and hybridized with EGFP as the probe. RNA was isolated from mycelia or infected rice leaves with the TRIzol reagent (Invitrogen) and mRNA was purified with the PolyA Ttract mRNA isolation kit (Promega Corp., Madison, WI, U.S.A.). The SMART RACE cDNA Amplification Kit (BD Bioscience Clontech) was used for cDNA synthesis and 5' RACE PCR. The specific primer used for 5' RACE was reverse primer NRace (Table 3). Pro-

Table 3. Polymerase chain reaction primers used in this study

\begin{tabular}{|c|c|}
\hline Names & Sequence $\left(5^{\prime} \rightarrow 3^{\prime}\right)$ \\
\hline NRace & GCGGCGTCCTGCCGTGTGGATTTGGATT \\
\hline PMR7 & ATTGGGTACTCAAATTGGTTCGGACAAGGTCATAATGT \\
\hline PMF8 & CAGCTCCTCGCCCTTGCTCACCTTTAGCAAAAAGCCACC \\
\hline PMF13 & CAGCTCCTCGCCCTTGCTCACGATTTCCAGATGCGTCTT \\
\hline PMF17 & GTCGAGCTCTCGAGTGGATTGGTAAGTTT \\
\hline PMR18 & ATAAGAATGCGGCCGCGGCCGGCCCTAGAGTATACCCAGCTA \\
\hline PMF19 & CGCGGATCCGGCGCGCCTAAAGATTTGTGTAATTT \\
\hline PMR20 & AAAACTGCAGATGACGAGACCGAGATTG \\
\hline PMF21 & CAGCTCCTCGCCCTTGCTCACCATTTTGGTTGCCAAGTT \\
\hline PMR22 & AGGAACCCAATCTTCAAAATGTGCGCCAAAAAGACAA \\
\hline PMF23 & ATTGGGTACTCAAATTGGTTACAGCAGCACGAGGTGAT \\
\hline PMF24 & ATTGGGTACTCAAATTGGTTGTTCCATCTCTTGATTGA \\
\hline PMF25 & ATTGGGTACTCAAATTGGTTTCGTCGCCATCCAACATT \\
\hline PMF28 & TTCGCCCGGAATTAGCTTGGCTGCAGGATTTCCAGATGCGTCTT \\
\hline PMR29 & CAGTTGACTGTATCGCCGGAATTCTGCGCCAAAAAGACAACCAA \\
\hline PMF30 & TCGCCCGGAATTAGCTTGGCTGCAGTCACTTTAGCAAAAAGCCA \\
\hline PMR32 & AGATCGAATTAGGATCCTCTGCTAGCCTCAGCAGTGCCAGGAAG \\
\hline PMF33 & TGCAGTAATACGACTCACTATAGGGTCACTTTAGCAAAAAGCCA \\
\hline PMR34 & ATCGAATTAGGATCCTCTGCTAGCTGCGCCAAAAAGACAACCAA \\
\hline PMF36 & ATTGGGTACTCAAATTGGGACGTGATTGTCTCGCAA \\
\hline PMF37 & CTTGATTGATAGACAGTACAACTCGAGGTTCAAAATACAAATGGTTG \\
\hline PMR38 & CAACCATTTGTATTTTGAACCTCGAGTTGTACTGTCTATCAATCAAG \\
\hline PMF39 & CAGATCATTGACCTGAACTCGAGCTAAACTCACATGAAGGC \\
\hline PMR40 & GCCTTCATGTGAGTTTAGCTCGAGTTCAGGTCAATGATCTG \\
\hline PMF45 & CAACCCCGTACGCGTTTTGTCGCCATCCAACAT \\
\hline PMR46 & ATGTTGGATGGCGACAAAACGCGTACGGGGTTG \\
\hline PMF47 & CTTGATTGATAGACAGTACTCACATGAAGGCTCTCGTA \\
\hline PMR48 & TACGAGAGCCTTCATGTGAGATCTGTCTATCAATCAAG \\
\hline PMF49 & GCTACCAGCCCTGAGGACGTCACAGAGTTT \\
\hline MG129Q1 & CGGCCGAGTTCCTCGAGT \\
\hline MG129Q2 & CGTCTCGAACTTGATCTTCTTGG \\
\hline ActQ1 & TCTTCGAGACCTTCAACGCC \\
\hline ActQ2 & ACCGGAGTCGAGCACGATAC \\
\hline Act5F & ACAGGGACCAGACAGCTT \\
\hline Act6R & GTGGTAGAGAAGGTGTAA \\
\hline
\end{tabular}


grams FoldIndex, DisEMBL, GLOBPROT 2, and DISOPRED2 were used to search for unstructured protein regions. PFSCAN, SAPS, and Pfam were used for protein domain and motif searches.

\section{Assays for germination, appressorium formation, penetration, and plant infection.}

Conidia harvested from 10-day-old oatmeal agar cultures were used for appressorium formation on plastic microscope coverslips (Fisher Scientific Co., Pittsburgh) or GelBond membranes (Cambrex, East Rutherford, NJ, U.S.A.) as described (Bruno et al. 2004; Li et al. 2004; Tucker et al. 2004). Appressorial penetration and infectious hyphal growth were assayed as previously described (Koga 1994; Koga et al. 2004; Xue et al. 2002). Expression of EGFP in appressoria and infectious hyphae was examined after $48 \mathrm{~h}$ of incubation with a Nikon Eclipse E800 epifluorescence microscope (Tokyo) or a Bio-Rad MRC 1024 UV/Vis System confocal laser scanning microscopy (Hercules, CA, U.S.A.). Two-week-old seedlings of rice cvs. CO-39, M201, and M202 and 8-day-old seedlings of barley cv. Golden Promise and Kindred were used for infection assays (Park et al. 2004). Plant incubation and inoculation were performed as described (Talbot et al. 1993; Valent et al. 1991). Lesion formation was examined at $7 \mathrm{dpi}$ as described (Talbot et al. 1993; Xue et al. 2002).

\section{Quantitative real-time RT-PCR.}

RNAs were isolated from Guy11 mycelia grown in CM for 2 days and infected rice leaves at 5 dpi. First-strand cDNAs were synthesized with the ProtoScript First Strand cDNA Synthesis Kit (New England Biolabs, Ipswich, MA, U.S.A.) and used as templates for real-time RT-PCR. Primers MG129Q1 and MG129Q2 (Table 3) were used to amplify a 100-bp amplicon of MIRl. As an endogenous control, the $M$. grisea actin gene $M g A C T 1$ (MG03982) was amplified as a 101-bp amplicon with primers ActQ1 and ActQ2 (Table 3). Quantitative real-time RT-PCR was performed with the ABI 7700 Sequence detection system (Applied Biosystem, Foster City, CA, U.S.A.) using the QuantiTect SYBR-green PCR Master mix (Qiagen) as described previously (Flaherty and Dunkle 2005). To verify that the efficiencies of the $M I R I$ and $M g A C T 1$ amplifications were approximately equal, PCR reactions were performed with serial dilutions of cDNA templates. After the amplification efficiencies of $M I R I$ and $M g A C T 1$ were verified to be acceptable, relative quantification of the $M I R I$ transcripts was calculated by the $2^{-\Delta \Delta \mathrm{Ct}}$ method (Livak and Schmittgen 2001), with $M g A C T 1$ as the endogenous reference and the level of MIRI expression in the CM cultures assigned the value of 1 .

\section{Construction of the MIR1 gene replacement and EGFP-fusion vectors.}

A 758-bp fragment upstream from the MIRl gene was amplified with primers PMF17 and PMR18 (Table 3) and cloned between the SacI and NotI sites of pYK11 (Zhao et al. 2004) as pLL42. The 778-bp downstream fragment was amplified with primers PMF19 and PMR20 and cloned between the BamHI and PstI sites of pLL42 as pLL43. The MIRI gene replacement construct pLL44 was generated by cloning the $h p h$ cassette from pCX62 (Zhao et al. 2004) into the AscI and FseI sites of pLL43.

The yeast gap repair approach (Bourett et al. 2002; Raymond et al. 2002) was used to generate the EGFP fusion constructs. To generate the MIRl-EGFP fusion construct, a $2.7-\mathrm{kb}$ fragment containing the entire $M I R l$ gene and its $1.5-\mathrm{kb}$ upstream region was amplified with primers PMR7 and PMF8 (Table 3) and cotransformed with XhoI-digested pDL2 into
Saccharomyces cerevisiae XK1-25 (Bourett et al. 2002; Bruno et al. 2004). Plasmid pLL36 rescued from the resulting $\operatorname{Trp}^{+}$yeast transformants was sequenced to confirm that the MIRl gene was fused in-frame with EGFP. A similar approach was used to generate the $M I R 1^{1-122}$-EGFP fusion construct pLL37 and a MIR1-EGFP overexpression construct pLL46. To generate pLL37, primers PMF13 and PMR7 were used to amplify a $1.9-\mathrm{kb}$ fragment containing the native promoter region and the first 122 amino acid residues of MIR1. To construct pLL46, primers PMF8 and PMR22 were used to amplify the MIRI ORF.

\section{Promoter analyses of $M I R 1$.}

We also used the yeast gap repair approach to generate all the EGFP reporter constructs for $M I R 1$ promoter analysis. Primer pairs PMF21-PMR7, PMF21-PMF22, PMF21-PMF23, PMF21-PMF24, and PMF21-PMF25 were used to generate pLL47, pLL48, pLL49, pLL50, and pLL51 (Fig. 4), respectively, in which EGFP was under the control of a 1,487-, 1,066-, 756-, 458-, and 209-bp sequence upstream from MIRl. PCR products amplified with primer pairs PMF49-PMR48 and PMF47-PMF21 were used as the templates for overlapping PCR (Horton et al. 1990) to delete region A ( -433 to -361$)$ of the MIRl promoter (Fig. 5). The same approach was used to delete region $\mathrm{B}(-305$ to -209$)$ of the MIRI promoter with primer pairs PMF24-PMR46 and PMF45-PMF21. The resulting overlapping PCR fragments were cotransformed with XhoI-digested pDL2 into yeast strain XK1-25 to generate pLL60 and pLL61 (Fig. 5), in which EGFP was under the control of the MIRl promoter deleted of region A and region $\mathrm{B}$, respectively. All of the EGFP fusion constructs were confirmed by sequence analysis and linearized with PstI before fungal transformation.

\section{ACKNOWLEDGMENTS}

This work was supported by a grant from BARD to J. Xu and A. Sharon. We thank L. Dunkle and C. Woloshuk at Purdue University for critical reading of this manuscript. We also thank J. Flaherty and B. Bluhm for assistance with quantitative real-time RT-PCR, Z. Hou for $F$. graminearum transformation, S. Kang at Pennsylvania State University for providing the 'zooblot,' and C. Staiger for assistance with confocal microscopy.

\section{LITERATURE CITED}

Adachi, K., and Hamer, J. E. 1998. Divergent cAMP signaling pathways regulate growth and pathogenesis in the rice blast fungus Magnaporthe grisea. Plant Cell 10:1361-1373.

Aichinger, C., Hansson, K., Eichhorn, H., Lessing, F., Mannhaupt, G., Mewes, W., and Kahmann, R. 2003. Identification of plant-regulated genes in Ustilago maydis by enhancer-trapping mutagenesis. Mol. Gen. Genet. 270:303-314.

Balhadere, P. V., and Talbot, N. J. 2001. PDE1 encodes a P-type ATPase involved in appressorium-mediated plant infection by the rice blast fungus Magnaporthe grisea. Plant Cell 13:1987-2004.

Barhoom, S., and Sharon, A. 2004. cAMP regulation of "pathogenic" and "saprophytic" fungal spore germination. Fungal Genet. Biol. 41:317-326.

Basse, C. W., Stumpferl, S., and Kahmann, R. 2000. Characterization of a Ustilago maydis gene specifically induced during the biotrophic phase: Evidence for negative as well as positive regulation. Mol. Cell. Biol. 20:329-339.

Basse, C. W., Kolb, S., and Kahmann, R. 2002. A maize-specifically expressed gene cluster in Ustilago maydis. Mol. Microbiol. 43:75-93.

Bohnert, H. U., Fudal, I., Dioh, W., Tharreau, D., Notteghem, J. L., and Lebrun, M. H. 2004. A putative polyketide synthase peptide synthetase from Magnaporthe grisea signals pathogen attack to resistant rice. Plant Cell 16:2499-2513.

Bourett, T. M., Sweigard, J. A., Czymmek, K. J., Carroll, A., and Howard, R. J. 2002. Reef coral fluorescent proteins for visualizing fungal pathogens. Fungal Genet. Biol. 37:211-220. 
Brendel, V., Bucher, P., Nourbakhsh, I. R., Blaisdell, B. E., and Karlin, S. 1992. Methods and algorithms for statistical analysis of protein sequences. Proc. Natl. Acad. Sci. U.S.A. 89:2002-2006.

Bruno, K. S., Tenjo, F., Li, L., Hamer, J. E., and Xu, J. R. 2004. Cellular localization and role of kinase activity of $P M K 1$ in Magnaporthe grisea. Eukaryot. Cell 3:1525-1532.

Carroll, A. N., Sweigard, J. A., and Valent, B. 1994. Improved vectors for selecting resistance to hygromycin. Fungal. Genet. Newsl. 41:22.

Clergeot, P. H., Gourgues, M., Cots, J., Laurans, F., Latorse, M. P., Pepin, R., Tharreau, D., Notteghem, J. L., and Lebrun, M. H. 2001. PLS1, a gene encoding a tetraspanin-like protein, is required for penetration of rice leaf by the fungal pathogen Magnaporthe grisea. Proc. Natl. Acad. Sci. U.S.A. 98:6963-6968.

Cramer, R. A., and Lawrence, C. B. 2004. Identification of Alternaria brassicicola genes expressed in planta during pathogenesis of Arabidopsis thaliana. Fungal Genet. Biol. 41:115-128.

Dean, R. A., Talbot, N. J., Ebbole, D. J., Farman, M., Mitchell, T. K. Orbach, M. J., Thon, M., Kulkarni, R., Xu, J.-R., Pan, H., Read, N. D., Lee, Y.-H., Carbone, I., Brown, D., Oh, Y. Y., Donofrio, N., Jeong, J. S., Soanes, D. M., Djonovic, S., Kolomiets, E., Rehmeyer, C., Li, W. Harding, M., Kim, S., Lebrun, M.-H., Bohnert, H., Coughlan, S., Butler, J., Calvo, S., Ma, L.-J., Nicol, R., Purcell, S., Nusbaum, C., Galagan J. E., and Birren, B. W. 2005. The genome sequence of the rice blast fungus Magnaporthe grisea. Nature 434:980-986.

de Jong, J. C., McCormack, B. J., Smirnoff, N., and Talbot, N. J. 1997. Glycerol generates turgor in rice blast. Nature 389:244-245.

Dyson, H. J., and Wright, P. E. 2005. Intrinsically unstructured proteins and their functions. Nat. Rev. Mol. Cell Biol. 6:197-208.

Ebbole, D. J., Jin, Y., Thon, M., Pan, H. Q., Bhattarai, E., Thomas, T., and Dean, R. 2004. Gene discovery and gene expression in the rice blast fungus, Magnaporthe grisea: Analysis of expressed sequence tags. Mol. Plant-Microbe Interact. 17:1337-1347.

Farfsing, J. W., Auffarth, K., and Basse, C. W. 2005. Identification of cisactive elements in Ustilago maydis mig2 promoters conferring highlevel activity during pathogenic growth in maize. Mol. Plant-Microbe Interact. 18:75-87.

Farman, M. L., and Leong, S. A. 1998. Chromosome walking to the AVR1-CO39 avirulence gene of Magnaporthe grisea: Discrepancy between the physical and genetic maps. Genetics 150:1049-1058.

Flaherty, J. E., and Dunkle, L. D. 2005. Identification and expression analysis of regulatory genes induced during conidiation in Exserohilum turcicum. Fungal Genet. Biol. 42:471-481.

Freitag, M., Hickey, P. C., Raju, N. B., Selker, E. U., and Read, N. D. 2004. GFP as a tool to analyze the organization, dynamics and function of nuclei and microtubules in Neurospora crassa. Fungal Genet. Biol. 41:879-910

Gilbert, M. J., Thornton, C. R., Wakley, G. E., and Talbot, N. J. 2006. A Ptype ATPase required for rice blast disease and induction of host resistance. Nature 440:535-539.

Horton, R. M., Cai, Z. L., Ho, S. N., and Pease, L. R. 1990. Gene-splicing by overlap extension-tailor-made genes using the polymerase chainreaction. Biotechniques 8:528-535.

Hou, Z. M., Xue, C. Y., Peng, Y. L., Katan, T., Kistler, H. C., and Xu, J. R. 2002. A mitogen-activated protein kinase gene $(M G V 1)$ in Fusarium graminearum is required for female fertility, heterokaryon formation, and plant infection. Mol. Plant-Microbe Interact. 15:1119-1127.

Irie, T., Matsumura, H., Terauchi, R., and Saitoh, H. 2003. Serial Analysis of Gene Expression (SAGE) of Magnaporthe grisea: Genes involved in appressorium formation. Mol. Genet. Genomics 270:181-189.

Jia, Y., McAdams, S. A., Bryan, G. T., Hershey, H. P., and Valent, B. 2000. Direct interaction of resistance gene and avirulence gene products confers rice blast resistance. EMBO (Eur. Mol. Biol. Organ.) J. 19:40044014

Kamakura, T., Yamaguchi, S., Saitoh, K., Teraoka, T., and Yamaguchi, I 2002. A novel gene, $C B P 1$, encoding a putative extracellular chitinbinding protein, may play an important role in the hydrophobic surface sensing of Magnaporthe grisea during appressorium differentiation. Mol. Plant-Microbe Interact. 15:437-444

Kang, S. C., Sweigard, J. A., and Valent, B. 1995. The PWL host specificity gene family in the blast fungus Magnaporthe grisea. Mol. PlantMicrobe Interact. 8:939-948.

Kim, S., Ahn, I. P., Rho, H. S., and Lee, Y. H. 2005. MHP1, a Magnaporthe grisea hydrophobin gene, is required for fungal development and plant colonization. Mol. Microbiol. 57:1224-1237.

Koga, H. 1994. Hypersensitive death, autofluorescence, and ultrastructural-changes in cells of leaf sheaths of susceptible and resistant nearisogenic lines of rice $(\mathrm{PI}-\mathrm{Z}(\mathrm{T}))$ in relation to penetration and growth of Pycularia oryza. Can. J. Bot. 72:1463-1477.

Koga, H., Dohi, K., Nakayachi, O., and Mori, M. 2004. A novel inoculation method of Magnaporthe grisea for cytological observation of the infection process using intact leaf sheaths of rice plants. Physiol. Mol Plant Pathol. 64:67-72.

Li, L., Xue, C. Y., Bruno, K., Nishimura, M., and Xu, J. R. 2004. Two PAK kinase genes, CHM1 and MST20, have distinct functions in Magnaporthe grisea. Mol. Plant-Microbe Interact. 17:547-556.

Livak, K. J., and Schmittgen, T. D. 2001. Analysis of relative gene expression data using real-time quantitative PCR and the 2(T)(-Delta Delta C) method. Methods 25:402-408.

Nakai, K., and Horton, P. 1999. PSORT: A program for detecting sorting signals in proteins and predicting their subcellular localization. Trends Biochem. Sci. 24:34-35.

Orbach, M. J., Farrall, L., Sweigard, J. A., Chumley, F. G., and Valent, B. 2000. A telomeric avirulence gene determines efficacy for the rice blast resistance gene Pi-ta. Plant Cell 12:2019-2032.

Pagni, M., Ioannidis, V., Cerutti, L., Zahn-Zabal, M., Jongeneel, C. V., and Falquet, L. 2004. MyHits: A new interactive resource for protein annotation and domain identification. Nucleic Acids Res. 32:332-335.

Park, G., Xue, G. Y., Zheng, L., Lam, S., and Xu, J. R. 2002. MST12 regulates infectious growth but not appressorium formation in the rice blast fungus Magnaporthe grisea. Mol. Plant-Microbe Interact. 15:183-192.

Park, G., Bruno, K. S., Staiger, C. J., Talbot, N. J., and Xu, J. R. 2004 Independent genetic mechanisms mediate turgor generation and penetration peg formation during plant infection in the rice blast fungus. Mol. Microbiol. 53:1695-1707.

Peng, Y. L., Shirano, Y., Ohta, H., Hibino, T., Tanaka, K., and Shibata, D. 1994. A novel lipoxygenase from rice - primary structure and specific expression upon incompatible infection with rice blast fungus. J. Biol. Chem. 269:3755-3761.

Raymond, C. K., Sims, E. H., and Olson, M. V. 2002. Linker-mediated recombinational subcloning of large DNA fragments using yeast. Genome Res. 12:190-197.

Sambrook, J., and Russell, D. 2001. Molecular Cloning: A Laboratory Manual. Cold Spring Harbor Laboratory Press, Cold Spring Harbor, NY, U.S.A

Soundararajan, S., Jedd, G., Li, X. L., Ramos-Pamplona, M., Chua, N. H. and Naqvi, N. I. 2004. Woronin body function in Magnaporthe grisea is essential for efficient pathogenesis and for survival during nitrogen starvation stress. Plant Cell 16:1564-1574.

Sweigard, J. A., Carroll, A. M., Kang, S., Farrall, L., Chumley, F. G., and Valent, B. 1995. Identification, cloning, and characterization of $P W L 2$, a gene for host species specificity in the rice blast fungus. Plant Cell 7:1221-1233.

Talbot, N. J. 2003. On the trail of a cereal killer: Exploring the biology of Magnaporthe grisea. Annu. Rev. Microbiol. 57:177-202.

Talbot, N. J., Ebbole, D. J., and Hamer, J. E. 1993. Identification and characterization of $M P G 1$, a gene involved in pathogenicity from the rice blast fungus Magnaporthe grisea. Plant Cell 5:1575-1590.

Thara, V. K., Fellers, J. P., and Zhou, J. M. 2003. In planta induced genes of Puccinia triticina. Mol. Plant Pathol. 4:51-56.

Trail, F., and Common, R. 2000. Perithecial development by Gibberella zeae: A light microscopy study. Mycologia 92:130-138.

Tucker, S. L., and Talbot, N. J. 2001. Surface attachment and pre-penetration stage development by plant pathogenic fungi. Annu. Rev. Phytopathol. 39:385-419.

Tucker, S. L., Thornton, C. R., Tasker, K., Jacob, C., Giles, G., Egan, M., and Talbot, N. J. 2004. A fungal metallothionein is required for pathogenicity of Magnaporthe grisea. Plant Cell 16:1575-1588.

Urban, M., Bhargava, T., and Hamer, J. E. 1999. An ATP-driven efflux pump is a novel pathogenicity factor in rice blast disease. EMBO (Eur. Mol. Biol. Organ.) J. 18:512-521.

Valent, B., and Chumley, F. G. 1991. Molecular genetic analysis of the rice blast fungus Magnaporthe grisea. Annu. Rev. Phytopathol. 29:443-467.

Valent, B., Farral, L., and Chumley, F. G. 1991. Magnaporthe grisea genes for pathogenicity and virulence identified through a series of backcrosses. Genetics 127:87-101.

Wright, P. E., and Dyson, H. J. 1999. Intrinsically unstructured proteins: Re-assessing the protein structure-function paradigm. J. Mol. Biol. 293:321-331

Xue, C. Y., Park, G., Choi, W. B., Zheng, L., Dean, R. A., and Xu, J. R. 2002. Two novel fungal virulence genes specifically expressed in appressoria of the rice blast fungus. Plant Cell 14:2107-2119.

Zhao, X. H., Xue, C., Kim, Y., and Xu, J. R. 2004. A ligation-PCR approach for generating gene replacement constructs in Magnaporthe grisea. Fungal Genet. Newsl. 51:17-18.

Zhao, X. H., Kim, Y., Park, G., and Xu, J. R. 2005. A mitogen-activated protein kinase cascade regulating infection-related morphogenesis in Magnaporthe grisea. Plant Cell 17:1317-1329.

Zheng, L., Campbell, M., Murphy, J., Lam, S., and Xu, J. R. 2000. The $B M P 1$ gene is essential for pathogenicity in the gray mold fungus $B o$ trytis cinerea. Mol. Plant-Microbe Interact. 13:724-732. 


\section{AUTHOR-RECOMMENDED INTERNET RESOURCES}

AIST Computational Biology Research Center's Tfsearch program: www.cbrc.jp/research/db/TFSEARCH.html

European Molecular Biology Laboratory's (EMBL) intrinsic protein disorder prediction DisEMBL server: dis.embl.de

EMBL's intrinsic protein disorder, domain, and globularity prediction GLOBPROT 2 server: globplot.embl.de

Sanger Institute's Pfam database: www.sanger.ac.uk/Software/Pfam

Stanford University's SAPS (statistical analysis of protein sequences) server: www.isrec.isb-sib.ch/software/SAPS_form.html

Swiss Institute of Bioinformatics PFSCAN database: hits.isb-sib.ch/cgi-bin/index

University College London Bioinformatics Unit's DISOPRED2 disorder prediction server: bioinf.cs.ucl.ac.uk/disopred

University of Pennsylvania's Transcription Element Search System (TESS) program: www.cbil.upenn.edu/cgi-bin/tess/tess

University of Tokyo Human Genome Center's PSORT server: psort.ims.u-tokyo.ac.jp

Weizmann Institute of Science's FoldIndex website: bip.weizmann.ac.il/fldbin/findex 